\title{
Researching the Politics of Illegal Activities
}

Max Gallien, Institute of Development Studies

ABSTRACT Although an object of increasing interest, researching illegal activities generates a range of methodological challenges for political scientists. Rather than an exhaustive discussion, this article provides a simple framework that structures these challenges. It highlights that illegality is an insufficient guide to method development and needs to be supplemented by an analysis of three dimensions in addition to legality: enforcement, normalization, and ethics. The article explains that beyond providing insight into the feasibility and challenges of different methodologies, examining these dimensions also directly points researchers to key political science questions about illegal activities.

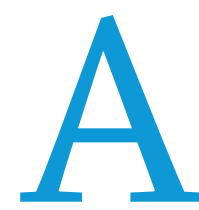

lthough traditionally regarded as a niche area within the discipline, illegal activities have clear empirical and theoretical relevance to political science. They stand at the heart of billion-dollar industries, from narcotics to prostitution, and relate to key conceptual concerns, from state capacity to the distributive politics of law enforcement. These connections have been highlighted recently in scholarship on activities ranging from smuggling (Ahmad 2017; Andreas 2014; Gallien 2020) to prison gangs (Lessing 2017; Skarbek 2014) and from sex work (Majic 2014) to street vending (Holland 2017). Literature on corruption and state crime has been a part of the field for even longer.

In the process, these scholars provided practical methodological examples of the study of illegal activities in political science. However, so far there has been no wider discussion or mapping within political science about how the methodological challenges of studying illegal activities relate to the discipline. This perhaps is unsurprising because relevant methodological debates are ongoing in neighboring disciplines such as economics and criminology (Gadd, Karstedt, and Messner 2012; Noaks and Wincup 2004). As this article shows, however, there is value in mapping these challenges and exploring how they connect to the interests of political science scholars and students more explicitly.

Given the diversity of illegal activities and their political contexts, the methodological challenges in studying them are extremely varied-this article does not exhaustively map them and is not divided along their typical categorization. ${ }^{1}$ Instead, its purpose is twofold. First, the article provides a simple framework

Max Gallien (iD is a fellow at the Institute of Development Studies. He can be reached at M.Gallien@ids.ac.uk. that delineates and maps key methodological challenges in studying illegal activities. Whereas the illegality of an activity is what situates it in this field of study, illegality alone provides insuffient guidance on the methodological challenges involved. Instead, this article suggests a mapping of the four relevant dimensions: legality, enforcement, normalization, and ethics. Second, the article shows that analyzing these dimensions not only structures methodological challenges but also frames and points to research opportunities because each dimension also is directly related to thematic political science interests in illegal activities.

\section{LEGALITY}

Activities are made illegal by their incongruity with legislation. ${ }^{2}$ The first defining feature of the study of illegal activities is that, as a field, its boundaries are defined by laws. Consequently, it is relational and context specific. Its boundaries are localized in time and space-what is illegal in present-day Netherlands and Antebellum Louisiana naturally differs. When illegal markets cross borders, global dynamics complicate the picture: whereas cannabis cultivation in Morocco is illegal, it is legal in parts of the United States, with both legal and illegal producers competing on the same global market. ${ }^{3}$ In activities that involve multiple people, laws may distinguish among roles-for example, in the case of "sex-buyer laws" that make paying for sex illegal but not selling it.

The illegality of an activity provides a natural starting point for identifying methodological challenges. This is because incongruity with legislation can trigger direct consequences such as formal procedures including government-administered research permits and security clearances. Similarly, illegality can trigger different formal ethics and insurance procedures. However, as highlighted in this article, the majority of methodological challenges in 
studying illegal activities are not merely unconditional consequences of illegality but are instead consequences of a law's enforcement, normalization, and ethics.

None of this makes legality irrelevant. Unpacking the legal status of activities not only provides a starting point to method development but also directly engages a project with their politics. It is a
Given the role of enforcement in structuring methodological challenges, it is unsurprising that much research on illegal activities has been conducted in contexts in which enforcement is limited or completed, from a rich literature on street vending to historical studies of organized crime. However, understanding the enforcement environment also can help researchers study activ-

\section{The first defining feature of the study of illegal activities is that, as a field, its boundaries are defined by laws. Consequently, it is relational and context specific.}

reminder that the illegality of an activity is not primarily a feature of the activity but rather a relationship with a legal framework, which is the product of a political process. Criminalization is a productive process, producing economic and political opportunities and asymmetries for state- and non-state actors (Andreas and Nadelmann 2008). Consequently, analysis of the politics of legalization and criminalization provides not only a starting point for methodological development but also for a political analysis of illegal activities. As such, it is a necessary starting point but not a sufficient one.

\section{ENFORCEMENT}

The illegality of an activity does not necessarily imply that laws against it are enforced: enforcement could be prevented by low state capacity, corruption, or "forbearance" (Holland 2016). Enforcement in this sense describes the mechanisms through which laws are enforced, the likelihood and predictability of detection, and the actors involved. If enforcement were merely down to the capacity of police and customs officers, the likelihood of detection could be purely probabilistic. However, scholarship on informal arrangements and moral economies highlights that, at times, the nonenforcement of laws is structured and predictable, resulting from local agreements, norms, or established practices of bribery (Gallien and Weigand 2021; Titeca and Flynn 2014).

If the legality of an act has limited direct consequences for research methodology, the enforcement of these laws is substantially more consequential. For example, enforcement has critical implications for the risks that exchanges of information imply for researchers and participants. In a context of predictable nonenforcement, information that researchers learn from participants is less likely to put participants at risk of law-enforcement operations. ${ }^{4}$ This facilitates learning between researchers and participants and decreases security risks for researchers with respect to both enforcement agencies and those involved in the activities.

For example, understanding the boundaries of enforcement was a key element of developing my research methodology when I interviewed smugglers in North Africa. Some networks trading selected goods had to make substantive efforts to evade law enforcement whereas others were broadly tolerated. Understanding which was which informed the questions that I could ask without changing the tone of an interview and helped to build trusting relationships. This was critical to both my ethics and security strategy: given high law enforcement presence in the bordertown and a necessity to interact with them, it was imperative for me not to gain information that made these interactions a risk for smugglers, thereby making my presence unwelcome. Explicit conversations with smugglers about the enforcement environment deepened their ability to give informed consent to our interactions and contributed to my security. ities where related laws are stringently enforced. Researchers can seek to learn from more tolerated variants of an activity about the structures, logic, and features of its less-tolerated variants. Alternatively, scholars can devise research strategies based on information that relates to such activities but does not aid enforcement against them. They can study activities that already have seen enforcement happen-such as completed court cases against gang leaders. Alternatively, researchers can seek to systematically limit information in a way that makes it less conducive to enforcement and limits the suspicions of researchers' cooperation with enforcement. In some of my work, this included focusing questions exclusively on institutions and regularities in illegal interactions rather than on individuals involved in them.

Like legality, enforcement is politicial. Consequently, analyzing enforcement environments is not only methodologically necessary but also part of a political analysis. It is well established that the relationship between enforcement data and the actual prevalence of illegal activities is spurious: an increase in arrests for heroin consumption, for example, can just as easily reflect an increase in consumption as an increase in enforcement-or only its reportingdue to political priorities or elite conflicts. Researchers must study the politics of enforcement to correctly interpret enforcement data-but, critically, this also presents opportunities for novel research questions, as scholarship on the distributive politics of enforcement, for example, demonstrates (Holland 2017; Tendler 2002).

\section{NORMALIZATION}

If both legality and enforcement primarily describe the relationship between illegal activities and the state, normalization describes the relationship between illegal activities and communities. As such, it spans two issues-the normative evaluation of activities (mirroring legality) and the consequences of these evaluations (mirroring enfocement). Whereas the latter can mirror state enforcement through organizations such as neighborhood watch groups or informal justice systems, it also can be reflected more subtly in social hierarchies. Notably, the position of illegal activities within normative perceptions is not necessarily uniform: as scholars of legal pluralism and hybrid governance highlighted, multiple perceptions and norms typically coexist within a social space (Cleaver 2015; Reyntjens 2016).

Like enforcement, the normalization of illegal activities directly influences the risks involved in information sharing. Methodologically, it is critical to consider that if illegal activities are tolerated by state enforcement but not socially normalized, then those speaking openly about them still may be exposed to sanctions within their community. Consequently, understanding the normalization of an activity presents another step in understanding which precautions are needed to limit risks to participants. 
Again, understanding these structures also can help develop methods that study more normalized activities in order to understand less normalized activities.

In addition to outlining the limits and risks of methodologies, however, understanding the normalization of illegal activities can inform research more directly. Studying normalization can highlight the language in which activities are embedded. Different terms frequently exist for illegal activities, some of which may be associated with shame or evasion, whereas others may be associated with ingenuity and survival; the "hustle" in "project living" presents a well-documented example (Venkatesh 2002). Analyzing language is critical for methodologies that rely on conversations with community members. In her work on mobility across the US-Mexican border, Sanchez $(2014,13)$ highlighted how much easier conversations around illegal activities become when they are locally normalized and embedded in a discourse of "things that can be spoken about." In my own research, even if smugglers recognized their activity as illegal, language around "business" and "trade" provided a better vocabulary for interviews, building on normalized discourses that did not imply judgment. This point is not limited to ethnographies or interviews-surveys, for fundamental challenge: the management of divisions between normative evaluations by researchers and institutional frameworks. Because researchers are witnessing illegal activities, their respective responsibility toward legal frameworks, participants, their universities, and their own wellbeing can be placed in conflict with one another. Formal risk procedures, for example, may forbid a debriefing with participants that a researcher's own beliefs deem essential. That is, researchers' positions on ideologically controversial illegal activities (e.g., prostitution and proselytism) may put them at odds with their professional community.

I do not review these dynamics at length-a productive literature has increasingly developed around them ${ }^{6}$-but I do note that separating ethics from illegality and situating it in the context of normalization and enforcement highlights two points. First, ethical challenges also do not follow only from illegality but rather from a wider context, in which there are substantial informational assymetries between researchers and institutions. Second, because ethical challenges translate into methodological challenges, they are dependent on the norms of researchers, in addition to and beyond any formal ethical procedures and positions of their institution. In an age of increasing bureaucratization of research

\section{In an age of increasing bureaucratization of research ethics, work on illegal activities is a reminder that the ethical challenges of research are anchored not only in law but also in the positionality of the researchers.}

example, similarly require a precise understanding of the vocabulary used locally in order to generate meaningful questions and understand responses.

Again, understanding normalization both supports method development and suggests questions about the politics of these activities. Understanding social norms around illegal activities, as highlighted by critical work on hybrid governance, points to their embeddedness in historical processes and social hierarchies of power (Cleaver 2015; Meagher, Titeca, and De Herdt 2014). Understanding the politics of normalization also allows researchers to sidestep common clichés: the notions that because an activity is normalized, it is not "actually illegal" and that "the boundaries of legality are blurred" are common misinterpretations of the respective regulatory role of formal and informal norms that can be circumvented by an analysis of the power relationships sustaining them. Neither toleration nor normalization erases all power relationships created through an activity's illegality but they provide a starting point for their analysis.

\section{ETHICS}

Finally, what I term "ethics" connects an illegal activity to its normative evaluation not by the community in which it is embedded but instead by the community that studies it. ${ }^{5}$ This includes the rules about what constitutes correct behavior and research practice as formulated by Institutional Review Boards (IRB), as well as the personal normative beliefs of the researcher(s) and the wider community of scholars in a field.

Critically, these actors do not necessarily share one set of evaluations. A well-established difficulty in studying illegal activities is the need to adjust methodologies to fulfil IRB requirements and insurance procedures. However, this is only part of a more ethics, work on illegal activities is a reminder that the ethical challenges of research are anchored not only in law but also in the positionality of researchers.

Again, exploring these dynamics brings into focus an additional aspect of the politics of illegal activities. It points to the research community and its normative positions as a set of involved rather than detatched actors, and it asks who the relevant moral entity is within the context of modern academic work. For example, if junior researchers are conducting fieldwork and local research assistants and senior project principal investigators disagree on the ethics of a given intervention, the result will depend not only on the studied activities but also on the perspective and incentives of the researchers and the power structures within research institutions.

\section{ILLEGAL ACTIVITIES AND POLITICAL SCIENCE RESEARCH}

The methodological challenges in researching illegal activities do not follow only from illegality. This article highlights four dimensions that structure them: legality, enforcement, normalization, and ethics. I argue that these dimensions, albeit frequently conflated, can provide a simple framework to support methodological development on the study of illegal activities. Furthermore, this framework also highlights how method development and analysis are intertwined, pointing researchers to the relationship between the contexts that shape their methods and central political science questions about illegal activities.

Although the focus of this article is the segmentation of these dimensions of illegal activities, it is worth highlighting that they still are interconnected, in both their politics and methodological challenges. Key areas of study are clustered where enforcement is low and normalization high and, therefore, where there are fewer 
risks in information transmission (e.g., street vending and informal manufacturing) and where the reverse combination is true (e.g., narcotics trafficking). Yet, as this article highlights, overlooking or conflating these dimensions can lead project managers to misunderstand the challenges involved-for example, judging wider discussions-for example, regarding goods that are currently undergoing legalization processes (e.g., cannabis). Finally, as this article highlights, frank examinations of methodological challenges can contribute to an analysis of the politics of illegal activities because they point to themes of interest to the discipline.

\section{Frank examinations of methodological challenges can contribute to an analysis of the politics of illegal activities because they point to themes of interest to the discipline.}

from toleration by state officials that an activity also is socially accepted can lead a researcher to overlook serious risks for participants.

From this discussion follows three observations. First, the importance of context is a central theme. Situating illegal activities within legality, enforcement, normalization, and ethics to develop effective methodologies requires a preliminary analysis that frames activities within their context. This highlights the utility of methodologies that prioritize more holistic analyses, such as political ethnography (Forrest 2017; Schatz 2009). Ethnographies provide a rich toolbox to study the normative environment of illegal activities and to understand unwritten patterns of behavior and regulation embedded in everyday practice. Wedeen (1999) argued that ethnography can be useful to fill in gaps between official demonstrations of obedience and ordinary experiences of resistance. In studying illegal activities, ethnography can do the same in reverse: that is, trace structures of regulation in the seemingly disobedient. Ethnography is particularly suited to problematize dominant categorizations-such as legality-and examine the power structures that maintain them. As Schatz (2017) explained, ethnographic thinking also involves a critical approach to data and their relationship to the researcher. In the context of illegal activities, where data availability and access are fraught with difficulties, this can point to limitations, blind spots, and the politics involved in the data-collection process.

Second, the importance of such preliminary context analysis in developing methods to study illegal activities is not limited to ethnographies. Survey studies of illegal activities require a precise understanding of normalization and enforcement to understand the vocabulary through which participants frame these issues. Quantitative work that draws on observable effects of illegal activities (e.g., arrests and prices) requires deep analysis of the enforcement context to draw causal inferences. This highlights the potential for more collaboration across approaches and work that draws on multiple methodologies. This may include preliminary stages of in-depth qualitative or interpretative work prior to larger data-collection efforts; collaborative projects in which different methodological approaches are sequenced; and quantitative work within subfields in which there is existing ethnographic work on which to draw. In each case, the framework discussed herein should be relevant across methodological approaches.

Third, despite the existence of parallel discussions in neighboring fields, political science may benefit from more discussion within the discipline on the challenges in studying illegal activities. As noted previously, these challenges may provide a focal point for discussions across methodologies within the discipline. Furthermore, political science scholarship can provide tools to examine and contextualize the political embeddedness of these
This article further structures discussions around these challenges and opportunities among researchers, supervisors, students, and the discipline more widely.

\section{ACKNOWLEDGMENTS}

This work was supported by funding from the Economic and Social Research Council (ESRC).

I thank Shandana Khan Mohmand, the editors, two anonymous reviewers, and the participants of the 2020 Institute of Development Studies Methods Week for their helpful comments on previous versions of this article. $=$

\section{NOTES}

1. Separate literature has developed these challenges, although not always explicitly connected to the study of illegal activities. Relevant recent publications on fieldwork in complex environments demonstrate this well (e.g., Grimm et al. 2020; Mac Ginty, Brett, and Vogel 2020).

2. Furthermore, laws can create distinctions between illegal activities(e.g., misdemeanors and felonies).

3. As if to illustrate the constantly changing contexts of illegal activities, Morocco's government has in early 2021 announced first steps toward the legalization of cannabis cultivation.

4. An important caveat, of course, is that the very presence of researchers can affect enforcement environments.

5. I focus on the norms of people and organizations and their relationships because a discussion of the objective morality of these activities or evaluation by the schools of moral philosophy is beyond the scope of this article.

6. For example, Stark (2012) and Fisher (2021).

\section{REFERENCES}

Ahmad, Aisha. 2017. Jihad \& Co.: Black Markets and Islamist Power. Oxford and New York: Oxford University Press.

Andreas, Peter. 2014. Smuggler Nation: How Illicit Trade Made America. Oxford: Oxford University Press.

Andreas, Peter, and Ethan Nadelmann. 2008. Policing the Globe: Criminalization and Crime Control in International Relations. Oxford and New York: Oxford University Press.

Cleaver, Frances. 2015. "In Pursuit of Arrangements That Work: Bricolage, Practical Norms and Everyday Water Governance." In Real Governance and Practical Norms in Africa: The Game of the Rules, ed. Tom De Herdt and Jean-Pierre Oliver de Sardan, 207-27. London: Routledge.

Fisher, Jonathan. 2021. "How I Dealt with My Ethics Committee, and Survived.” In The Companion to Peace and Conflict Fieldwork, ed. Roger Mac Ginty, Roddy Brett, and Birte Vogel, 17-33. Cham, Switzerland: Springer International Publishing. doi: 10.1007/978-3-030-46433-2_2.

Forrest, M. David. 2017. "Engaging and Disrupting Power: The Public Value of Political Ethnography." PS: Political Science \& Politics 5o (1): 109-13. doi: 10.1017/ S1049096516002250.

Gadd, David, Susanne Karstedt, and Steven Messner. 2012. The SAGE Handbook of Criminological Research Methods. London: SAGE Publications Ltd. doi: $10.4135 / 9781446268285$.

Gallien, Max. 2020. "Informal Institutions and the Regulation of Smuggling in North Africa." Perspectives on Politics 18 (2): 492-508. doi: 10.1017/S1537592719001026. 
Gallien, Max, and Florian Weigand. 2021. "Channeling Contraband: How States Shape International Smuggling Routes." Security Studies. doi: 10.108o/ 09636412.2021 .1885728 .

Grimm, Jannis, Kevin Koehler, Ellen Lust, Ilyas Saliba, and Isabell Schierenbeck. 2020. Safer Field Research in the Social Sciences: A Guide to Human and Digital Security in Hostile Environments. Thousand Oaks, CA: SAGE Publishing.

Holland, Alisha C. 2016. "Forbearance." American Political Science Review 110 (2): 232-46. doi: 10.1017/Sooo3055416000083.

Holland, Alisha C. 2017. "Forbearance as Redistribution: The Politics of Informal Welfare in Latin America." Cambridge Studies in Comparative Politics. Cambridge and New York: Cambridge University Press.

Lessing, Benjamin. 2017. "Counterproductive Punishment: How Prison Gangs Undermine State Authority." Rationality and Society 29 (3): 257-97. doi: 10.1177/1043463117701132.

Mac Ginty, Roger, Roddy Brett, and Birte Vogel. 2020. Companion to Peace and Conflict Fieldwork. New York: Springer International Publishing.

Majic, Samantha. 2014. "Sex Work Politics: From Protest to Service Provision." American Governance: Politics, Policy, and Public Law. Philadelphia: University of Pennsylvania Press.

Meagher, Kate, Kristof Titeca, and Tom De Herdt. 2014. "Unravelling Public Authority: Paths of Hybrid Governance in Africa." Justice and Security Research Programme Policy Brief. Research Brief \#10, March.

Noaks, Lesley, and Emma Wincup. 2004. Criminological Research. London: SAGE Publications Ltd. doi: 10.4135/9781849208789.
Reyntjens, Filip. 2016. "Legal Pluralism and Hybrid Governance: Bridging Two Research Lines." Development and Change 47 (2): 346-66. doi: 10.1111/dech.12221.

Sanchez, Gabriella. 2014. Human Smuggling and Border Crossings. New York: Taylor \& Francis Publishing.

Schatz, Edward. 2009. Political Ethnography. Chicago: University of Chicago Press. www.press.uchicago.edu/ucp/books/book/chicago/P/bo7995019.html.

Schatz, Edward. 2017. "Disciplines That Forget: Political Science and Ethnography." PS: Political Science \& Politics 50 (1): 135-38. doi: 10.1017/ S1049096516002304.

Skarbek, David. 2014. The Social Order of the Underworld: How Prison Gangs Govern the American Penal System. Oxford: Oxford University Press.

Stark, Laura. 2012. Behind Closed Doors: IRBs and the Making of Ethical Research. Chicago: University of Chicago Press.

Tendler, Judith. 2002. "Small Firms, the Informal Sector, and the Devil's Deal." IDS Bulletin 33 (3): 1-15. doi: 10.1111/j.1759-5436.2002.tboo035.x.

Titeca, Kristof, and Rachel Flynn. 2014. “'Hybrid Governance,' Legitimacy, and (Il)Legality in the Informal Cross-Border Trade in Panyimur, Northwest Uganda." African Studies Review 57 (01): 71-91. doi: 10.1017/asr.2014.6.

Venkatesh, Sudhir. 2002. "'Doin' the Hustle': Constructing the Ethnographer in the American Ghetto." Ethnography 3 (1): 91-111. doi: 10.1177/1466138102003001004.

Wedeen, Lisa. 1999. Ambiguities of Domination: Politics, Rhetoric, and Symbols in Contemporary Syria. Second Edition. Chicago: University of Chicago Press. 


\section{용 apsaEDUCATE}

\section{Introducing APSA Educate - A Library for Political Science Teaching and Learning Resources}

APSA Educate provides a centralized space to share and access teaching materials from syllabi to simulations.

The website is free to access and features a strong search function and easy submission form. Contributing a resource takes less than ten minutes!

\section{PLATFORM BENEFITS}

- Access a broad range of high-quality political science teaching and learning materials including syllabi, in-class activities, simulations, writing assignments, civic engagement tools, and more!

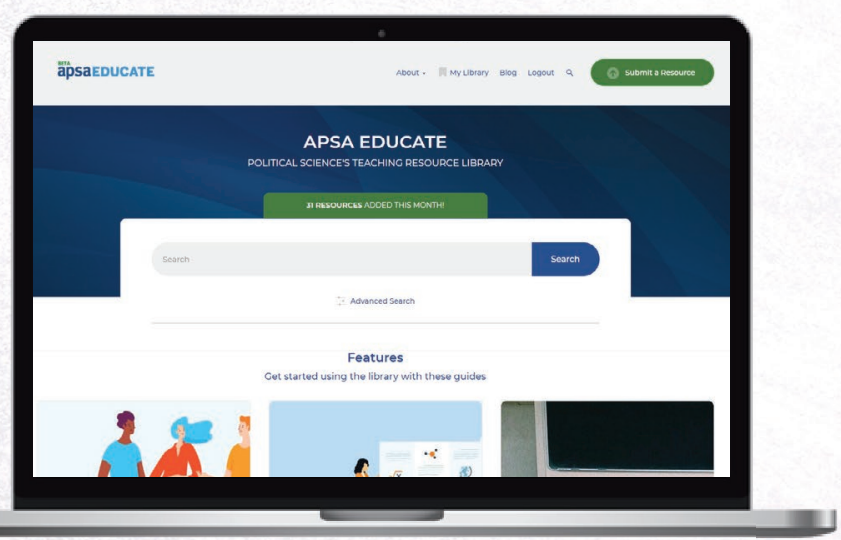

- Share your teaching materials and innovations with colleagues.

- Save favorite resources to your personal teaching resource library.

- Ask questions, discuss modifications to and experience with resources via comments.

- Learn from and share with colleagues through our Faculty Café Blog - featuring member-driven conversations around innovations, challenges, and best practices in political science education.

Learn more about APSA Educate, please visit educate.apsanet.org. 